\title{
Cooperación internacional al desarrollo: \\ escuchando al sur
}

\author{
Amador Hidalgo, Amanda \\ Universidad de La Laguna, Tenerife, España \\ amanda.ah93@hotmail.com
}

\section{RESUMEN}

Dada la importancia que recae sobre el análisis y la comprensión de la Cooperación Educativa Internacional al Desarrollo y todo lo que ella representa al situarse como una de las prioridades de la realidad social en la que nos encontramos, se considera interesante dar cabida a los diversos conceptos que dan forma y sentido a este ámbito y que deberían ser una prioridad social inequívoca. La desinformación, el desinterés y el miedo a lo desconocido han dado lugar a un profundo sentimiento de egoísmo y rechazo que se traduce, a su vez, en una enorme laguna a nivel de concienciación social. Del mismo modo, con el paso de los años, el mundo se ha ido conformando y estructurando en base a sus recursos y posibilidades, quedando los límites de cada porción definidos de forma poco equilibrada y siendo las consecuencias de todo este proceso las que asolan hoy esta realidad. Una información real, contrastada y constatada es la clave y la herramienta más eficaz para alcanzar el hasta hoy utópico Desarrollo. Por todo ello, con esta breve presentación de conceptos y modelos se busca profundizar en nuevas concepciones que atiendan a voces hasta hoy silenciadas. De esta forma, y con la intención de ir más allá de concepciones anquilosadas, se partirá desde una óptica humanizadora que permitirá dar presencia a voces experimentadas en este ámbito. Demostrando así no solo que el Sur tiene voz, sino que también tiene mucho que aportar(nos).

PALABRAS CLAVES: Cooperación Internacional al Desarrollo, Educación, África, Diálogos, Alternativos, Cooperación Sur-Norte.

\section{LA PESADILLA DE LO QUE ES Y LA VERDAD QUE YA NO IMPORTA}

«Las luchas más innovadoras y transformadoras ocurren en el Sur, en el contexto de realidades socio-político- culturales muy distintas, donde las concepciones sobre el ser y la vida son diferentes a la visión del individualismo occidental» Boaventura de Sousa Santos (2008).

Ya lo decía Calderón de La Barca: «todos sueñan lo que son, aunque ninguno lo entiende». Con el paso de los años, el mundo se ha ido conformado y estructurando en base a sus recursos y posibilidades, los límites y los márgenes de actuación de cada porción han sido definidos de forma poco equilibrada, siendo las consecuencias de todo este proceso las que asolan hoy nuestra realidad. La vida, su planteamiento y sus circunstancias han creado seres ambiciosos incapaces de discernir de forma justa entre lo deseado y lo deseable.

Si recurrimos al Diccionario de la Real Academia Española para consultar el significado del término Desarrollo, encontramos que este hace alusión (en su acepción número ocho) a la capacidad que tiene una comunidad humana para progresar o crecer, especialmente en el ámbito económico, social o cultural. Por tanto, toda limitación establecida atenta directamente contra la posibilidad de Desarrollo de determinados enclaves. En estas líneas se tratará de profundizar en las diferentes conceptualizaciones de Desarrollo y la Cooperación, atendiendo especialmente a las reflexiones surgidas desde el continente africano y desde una perspectiva que ponga en alza la importancia de diálogos diferentes. La intención de esta comunicación no es otra que realizar una breve revisión teórica que permita atisbar las raíces de los Diálogos Alternativos, enfatizar en su razón de ser y profundizar en una realidad que se ve día tras día cubierta por el velo de la indiferencia, por supuesto desde la óptica de la educación y su indiscutible potencialidad.

Las consecuencias injustificadas de un azaroso desgaste por parte de los países del Norte, la vulnerabilidad del Sur ante esta misma realidad, la impotencia y resignación de todos aquellos que la sufren, la imposibilidad de un cambio sin la entrada en escena de la educación y la ineludible actuación 
de la Cooperación como elemento conciliador, junto con la necesidad de poner un punto y aparte en la historia del Desarrollo de realidades aplacadas, sostienen la línea desarrollada, sostenida y defendida en este esbozo comunicativo.

Como educadores y educadoras no podemos olvidar todo lo que nos rodea más allá de nuestra propia realidad, las infinitas realidades carentes de un sistema educativo óptimo capaz de dar lugar a un cambio y un avance palpable en la calidad de vida de quienes desde el Sur piden a gritos una mayor visibilidad social y hacer frente a las injusticias a las que solo podemos poner fin a través de la educación. Tenemos en nuestras manos un enorme potencial infinitamente codiciado.

No podemos permitir que, en plena era de la comunicación y la información, la sociedad del Sur se convierta en un mero espectador de todo aquello que acontece en la otra cara del mundo mientras sus mandatarios miran hacia otro lado. Ya lo decía Kapuscinski (1932), la verdad dejó de ser importante cuando se descubrió que la información era un negocio.

Ante una situación tan aparentemente normalizada y regulada surgen, paradójicamente, cientos de problemas y alteraciones. Vivimos en una sociedad que, lejos de respetar el curso lógico de los hechos, se esfuerza en buscar la conflictividad en lo más natural, impidiendo de esta manera el cumplimiento de elementos que deberían ser inamovibles, como lo son los Derechos Humanos. Falsos prejuicios, etiquetas, sentimientos encontrados, odio injustificado, miedo a lo desconocido, egoísmo, etnocentrismo, egocentrismo o simplemente ausencia de tolerancia son, entre otros, los grandes protagonistas que se esfuerzan en afectar negativamente al Desarrollo del Sur. Se considera prioritario romper con todas estas falsas premisas, enfatizando en lo positivo de la diversidad, rompiendo mitos sobre las causas y las consecuencias la globalización, insistiendo en su impacto en el mundo actual y dando voz y cabida a los protagonistas de esta realidad. Sin perder jamás de vista los millones de personas que pagan hoy nuestros excesos y nuestro desconocimiento. Dejando volar para ello el velo de la indiferencia y la ignorancia que nos cubre y nubla la vista por momentos.

El doctor Mbuyi Kabunda Badi, profesor de Relaciones Internacionales y presidente de la Asociación Española de Africanistas (entre otros méritos), es uno de los grandes referentes de esta realidad y define el término Cooperación al Desarrollo como: «aquel trabajo conjunto entre el Norte y el Sur que contribuye a la búsqueda de soluciones globales para los problemas globales que hoy afectan al mundo». Hablamos por tanto de globalidad, de una globalidad que se extiende por los incontables kilómetros de la Tierra y que implica a los más de 7'442 miles de millones de personas que en ella vivimos. Una globalidad que hace que los problemas no sean individuales sino comunitarios y que requiere, consecuentemente, que las soluciones partan desde la propia comunidad. De una globalidad que no entiende de Norte ni de Sur, de pobreza ni de riqueza, que parta de la propia humanidad que nos caracteriza y asemeja y que trabaje en aras de un desarrollo global, comunitario, justo y equiparado.

Todo ello, partiendo siempre de la idea de que un conocimiento real y sincero sobre la realidad de los países del Sur es fundamental para la óptima actuación del Norte. Es primordial promover la transmisión de información clara y objetiva, huyendo en todo momento de aquello que pretenda contaminar esta realidad. Sin olvidar jamás que la concienciación es la clave más preciada para el cambio, imposible de conseguir sin confianza (confianza que se ha ido perdiendo a través de tanto engaño y tantas tergiversaciones). Se ha logrado que la sociedad deje a un lado los problemas globales, que olvide que su abrigo puede tornarse en frío en la otra cara del mundo, que sea capaz de explotar los recursos de quienes sin tener nada lo pierden todo. Pero lo que no podemos olvidar es, como bien decía Josep Giralt (2011), que ninguna causa que busque mejorar las condiciones de vida de las personas es inútil. La Cooperación al Desarrollo debe seguir siendo y estando hasta que las grandes desigualdades sean historia; entonces, sólo entonces, se tornará innecesaria.

¿Cómo concebir las fronteras y el reparto de nuestro planeta?, ¿Cómo entender, asimilar y respetar los límites de nuestros sueños, metas o aspiraciones? Cuando miles las personas que se ven, día tras día, encerradas en sí mismas, sin poder dar rienda suelta a su desarrollo personal y/o laboral, simplemente por haber nacido en determinado momento y/o en determinado lugar. Los sueños, las pasiones, las aspiraciones, las metas, las proyecciones de futuro o la simple supervivencia jamás deberían tener límites. Nadie debería poder tener el derecho de poner en pausa nuestras vidas, ni mucho menos de ponerle fin. Hay situaciones y realidades en las que nadie debería verse jamás y, sin embargo, son el pan de cada día de muchas personas. Más allá de las fronteras y barreras físicas, de las vallas, las verjas, el alambre, el cemento, el hormigón o las banderas, se esconden barreras generalmente invisibles al ojo humano pero profundamente dañinas. Hablamos de la discriminación, el egoísmo, el racismo, la xenofobia, el odio, el rechazo, la falta de educación y/o concienciación, 
la desconfianza, las etiquetas o la deshumanización. En ocasiones, es la propia sociedad la que se encarga de hacer las veces de límites fronterizos y, rozando la crueldad, se empeña en frustrar los intentos de Desarrollo del Sur.

Tras una realidad tan evidente y simultáneamente invisible, ante un silencio tan ensordecedor y tantas personas convertidas en cifras, el Desarrollo (o su inexistencia) pasa totalmente desapercibido en un Norte que no está dispuesto a ceder. Afectados fundamentalmente por terceros elementos, los países del Sur se ven constantemente cuestionados por quienes nada saben de ellos. Hablamos de fenómeno que pocos conocen, pero del que todos se atreven a hablar. Un fenómeno que afecta a millones de personas y que parece seguir sumido en un pasado improcedente y carente de sentido. El subdesarrollo del Sur pone en numerosas ocasiones en entredicho el cumplimiento de los Derechos Humanos, dotando aún de mayor vulnerabilidad al colectivo que nos concierne.

Entendiendo la vulnerabilidad como un riesgo, nos enfrentamos a una realidad que goza de dicha condición de forma inequívoca. Limitar las expectativas del Sur, hundir sus aspiraciones, mermar su capacidad de resiliencia y recuperación, hundir sus intentos y obligarlos a retroceder sobre sus pasos nos vuelve sujetos activos de su (muy) dura realidad. Es por ello que ante la necesidad de abrir muchos ojos, de romper con falsas informaciones, acabar con un miedo infundado y, sobretodo, respetar un proceso natural y humano, este pide a gritos una mayor visibilidad.

\section{COOPERACIÓN SUR-NORTE: ¿ES POSIBLE?}

La concepción de Desarrollo más relevante durante las décadas de los cincuenta y sesenta, planteaba la existencia de un Desarrollo lineal y único, válido para todas las realidades. Las sociedades del Sur (consideradas subdesarrolladas o atrasadas) debían seguir los pasos indicados por los países del Norte (considerados desarrollados y avanzados) para poder superar la situación en la que se encontraban. Esta interpretación económica de la realidad internacional en base a la desigualdad y los desequilibrios de las diversas regiones, se extendió también al ámbito cultural, dotando a las teorías asimilacionistas de mayor peso y presencia.

Tras nutrirse de las teorías evolucionistas (cuyo supuesto teórico subyacente sería el paralelismo cultural $^{1}$ ) se derivaría en la defensa de la cultura hegemónica occidental, sus valores, sus normas y su concepción de la realidad (siendo los suyos propios los únicos válidos a escala universal y concibiendo esta cultura como la única capaz de dar cabida a un Desarrollo óptimo). Este nuevo pensamiento hegemónico no daba cabida alguna a las pluralidades y la heterogeneidad, concibiendo como apto su único modelo de desarrollo. (González Pérez, 2014).

Habiendo pincelado y atisbado los orígenes de la equívoca concepción de Desarrollo, podemos afirmar y confirmar que los paralelismo con la actualidad son más que visibles y, por supuesto, necesariamente modificables. Desde la perspectiva de la Cooperación, cuando hablamos de diálogos, irremediablemente recurrimos a modelos convencionales y anclados en una concepción errónea de lo que es y supone la CID.

Olvidar las falsas relaciones de poder y supremacía, abrir la mente a nuevas formas de Cooperación, dar cabida a diversos agentes antes nunca recurridos e idear fórmulas para la consecución de un desarrollo óptimo debería ser una prioridad en los tiempos que corren. Se comenzó realizando una fría Cooperación Vertical y posteriormente se dio el salto a la Cooperación Horizontal, pero se olvidó que el Sur también tiene voz y mucho que aportar. Actualmente se habla del diálogo Sur-Sur como propuesta alternativa y modelo de cambio, pero se deja en el tintero la Cooperación Sur-Norte. Con todo ello, se debería indudablemente conceder mayor relevancia a los aportes del Sur, dado el estrepitoso fracaso de la búsqueda de soluciones a los problemas globales desde Occidente.

En esta búsqueda de alternativas, ¿es posible concebir la Cooperación Norte-Sur a la inversa?, ¿Existe un espacio reservado en esta realidad para el cambio de roles en el intercambio?, ¿Qué tiene

1 El paralelismo cultural implicaría que todas las sociedades pasen por idénticas fases de desarrollo en una misma escala evolutiva (generando así culturas más y menos desarrolladas). 
el Sur para aportar al Norte? Como bien señala Mbuyi Kabunda (2011), el mundo debería sostenerse en relaciones de mutualismo y reciprocidad. Del mismo modo en que un edificio se apoya sobre sus cimientos, el Norte se apoya en el Sur desde tiempos inmemoriales. De ahí que el peso de nuestro Desarrollo recaiga sobre sus espaldas.

Considerando interesante remontarnos al cortometraje «Binta y la Gran Idea», rodado en Senegal bajo la dirección de Javier Fesser y nominado al Óscar al Mejor Cortometraje en 2007, se recurre a una de las frases pronunciadas por la protagonista del mismo para ilustrar esta realidad: «Mi padre dice que debemos aprender del comportamiento de los pájaros. Los pájaros son tan listos que toman lo mejor del Norte y lo mejor del Sur». Y es que, siempre se necesita un poco de Sur para poder ver el Norte. El Sur necesita al Norte tanto como el Norte necesita al Sur. De ahí que no sea nada descabellada la idea de pensar que nuevos modelos de Cooperación basados en este concepto puedan resultar muy positivos para ambas realidades.

Sin embargo, hemos jugado a colonizarlo y modificarlo todo a nuestro antojo: territorios, consciencias, sociedades, mentalidades, ideologías, percepciones, metodologías, modelos, conceptos, teorías, ideas e incluso vidas. Hemos creído que teníamos el mundo a nuestros pies mientras jugábamos a transformarlo y modificarlo hasta dejarlo a nuestra medida, a nuestro gusto, a nuestro antojo. Olvidando para ello la diversidad, olvidando la libertad, olvidando los principios básicos y la ética (des) imperante. Durante los últimos años hemos podido ver cómo, lejos de avanzar, hemos retrocedido a pasos agigantados en estas cuestiones. Hemos visto como muchos mundos y realidades se han desplomado, desvanecido y roto en mil pedazos mientras permanecíamos expectantes desde la distancia, indiferentes y despreocupados en muchos casos. Hemos vivido inmensas barbaries y simplemente las hemos dejado correr con un poco de aire fresco.

Hemos dejado ver nuestra hipócrita generosidad y solidaridad, camufladas en falsas emociones y empatías inexistentes. Nos hemos refugiado detrás de nuestras cortinas de bienestar y hemos limpiado superficialmente nuestras consciencias haciendo uso de recurrentes y recurridas pronunciaciones, estereotipados e impersonales hashtags e incluso hemos sido capaces de abatirnos detrás de las pantallas, escudándonos en las redes sociales (apostando mucho por las redes y muy poco por lo social). Hemos empañado con lágrimas forzadas nuestras lentes de visión europeísta y visto empañados nuestros objetivos, principios y cotidianeidad.

A la par, hemos hecho lo (im)posible para que nuestro ritmo no se viese afectado en ningún momento, para que el efecto mariposa de la teoría del caos careciese totalmente de sentido, para que el batir de las alas de una mariposa en nuestro extremo opuesto, no pudiese afectar en lo más mínimo a nuestra cómoda, programada y calculada realidad. Para que las barreras sean cada vez más grandes, más altas y más fuertes, más impenetrables.

¿En qué momento hemos considerado que homogeneizarlo todo sería la clave del éxito social?, ¿Bajo qué premisas sostenemos la necesidad de igualar constantemente, a todas las escalas? Durante muchísimos años hemos tratado de dar espacio y cabida a una sociedad igual (que no igualitaria, ni mucho menos). Nos hemos empeñado con tesón y esfuerzo en uniformar en torno a Occidente, en eliminar toda cabida a la diversidad. Pero en esto no somos nuevos, había quienes lo intentaban mucho antes. Nos auto consideramos modernos pero llevamos el pensamiento único por bandera, la unificación, la homogenización y la homogeneidad. Nos ocultamos detrás de falsos conceptos y falsas premisas, pero realmente estamos estancados en plena modernidad.

\section{LO QUE PUEDE LLEGAR A SER}

«El Desarrollo no es ser tanto o mejor que los otros, sino todo lo que uno pueda llegar a ser» José Luis Sampedro

Efectivamente, la idea del Desarrollo como compensación de los problemas a los que nos enfrentamos en la actualidad ya no es atractiva y para los especialistas carece de sentido, simplemente porque la promesa del Desarrollo ya no consuela a nadie de la injusticia social existente y de tantas y tantas otras cosas que son sencillamente inaceptables. Sin embargo, la idea de Desarrollo como 
confirmación de que otro mundo es posible, como acicate para la lucha, como lugar alrededor desde el que debatir otra forma de vivir, radicalmente otra, cobra fuerza. (Pérez y Toledo, 2017)

Está claro que la simple existencia del término indica un avance, un progreso, un camino a seguir. Aunque desgraciadamente los plazos son infinitos y el camino es difícil, supone un logro encontrarnos en la senda del buen hacer. La Educación para la Cooperación al Desarrollo busca precisamente dar voz y protagonismo al Sur y emplazar los adoquines del camino hacia el equilibrio mundial. Durante años y años nos hemos ofuscado en designar y ejercer falsas relaciones de poder y en asignar falsos procesos de etiquetaje que han derivado, como no podía ser de otro modo, en la enorme desigualdad social existente y latente en la actualidad. Nuestra sociedad y todo lo que la compone se ha construido sobre las bases de falsas creencias y percepciones que han derivado en equívocas relaciones de poder, injustificados desequilibrios e insaciables sentimientos de egolatría, egocentrismo y etnocentrismo.

Con espíritu colonizador, Occidente se ha hecho dueño y señor de objetos inasignables; de realidades ajenas; de procesos de etiquetaje y encasillamiento injustificados e injustificables. Hemos aprovechado que la esperanza se desvanece cuando su objeto se hace inalcanzable para calmar nuestra sed de conquista, pero hemos olvidado que en la propia inalcanzabilidad también se halla el magnetismo que alimenta la expectación. Y que es precisamente ese magnetismo el que mantiene vivo a muchos, el que no permite que la llama descanse nunca, el motivo de que la lucha no haya cesado. (Díaz, 2008).

Si hay algo claro es que, el mundo, como tal, se ha dividido en dos: los que han hecho y los que no han tenido más remedio que dejarse hacer. Los que han sumado y a los que se ha restado. Los que han sometido y los que han sido sometidos. Los que han ganado y los que han perdido. El verdadero protagonismo es, cuanto menos cuestionable, en una balanza que tiene un claro e indudable (des)equilibrio. Y es que, los auténticos protagonistas han sido aquellos que han permitido que se crease todo sobre sus espaldas, los que han ejercido de sólidas bases, los que se han convertido involuntariamente en los cimientos de un proceso colonizador que actuaba únicamente preso de su avaricia incansable.

Es evidente que la persistencia de la dominación en la era postcolonial es una realidad que se ha extendido hasta nuestros días y que, de hecho, parece que seguirá manteniéndose a pesar de los pesares. La dominación ha calado tan hondo que se ha convertido prácticamente en un saber hegemónico que se traspasa de generación en generación, sobrepasando toda naturaleza humana, llegando más allá de cualquier pensamiento razonable.

Hemos dado lugar a una amplísima gama de etiquetajes y encasillamientos con el único propósito de dividir, segregar, diferenciar, difuminar. Al igual que Disney ha hecho con sus estereotipados personajes, nosotros hemos venerado a héroes erróneos, hemos malinterpretado sus rasgos definitorios y hemos empañado una realidad que pide a gritos transparencia. Si tenemos en cuenta el papel que juega la Cooperación Internacional al Desarrollo a la hora de dar cabida a las diversas alternativas que han ido surgiendo, no podemos dejar de apostar por un modelo que fusione la sabiduría y el conocimiento de las culturas tradicionales indígenas del Sur con la tecnología y la praxis del Norte. Queda demostrada la fuerza con la que el Sur puede irrumpir en las realidades del Norte y los muchos beneficios que puede proporcionarle. Lejos quedan las viejas concepciones misericordiosas y las falsas relaciones de poder que se han forjado durante décadas. Ha llegado el momento de escuchar todas aquellas voces que han sido silenciadas durante tanto tiempo y de dar cabida a los diálogos alternativos.

No queda ninguna duda de que estos diálogos alternativos se presentan como motores para un cambio mucho más respetado, humanizado, inclusivo y respetuoso. Optar por la Cooperación Sur-Norte realzando la importancia del conocimiento que puede aportar el Sur al Norte en lo que se referido a experiencias, conocimientos y prácticas significativas es una opción segura en esta realidad cambiante. Volviendo a las ideas de Boaventura de Sousa Santos (2008), ningún país es tan pobre como para no tener nada que ofrecer, ni ninguno tan rico como para no tener nada que aprender. En la misma línea, como premisa para desarrollar las epistemologías del Sur, también se considera fundamental enfatizar en la comprensión del mundo como algo mucho más amplio que la mera compresión occidental del mismo, de ahí que para la transformación sea necesario recurrir a vías, modos y métodos impensables para occidente.

Ha llegado el momento de romper con este sinsentido y trabajar de forma conjunta con nuevos diálogos de Cooperación que nos acerquen a un Desarrollo generalizado y extendido. Que borren las lagunas, anulen los abismos diferenciales y aboguen por una globalización justa y comunitaria para todos y cada uno de los países del mundo. Esto no será posible si la Cooperación Sur-Norte no logra 
cobrar protagonismo frente a la Cooperación Norte-Sur. Las soluciones las hallarán las personas que sufren los problemas en su propia piel y para ello el Norte deberá estar atento y colaborador a las propuestas que emanen desde el Sur.

\section{REFERENCIAS BIBLIOGRÁFICAS}

Andrés, Gonzalo y Molina, Ignacio (2000). Introducción a la Solidaridad Internacional: La Cooperación para el Desarrollo. Valladolid: Secretariado de Publicaciones e Intercambio Editorial de la Universidad de Valladolid.

Ayllón, Bruno y Surasky, Javier (2010): «La Cooperación Sur-Sur en Lationoamérica: Utopía y Realidad.» IUDC. Madrid: Catarata.

Bancet, Alice (2012): «Análisis de la Cooperación Triangular: Discursos y prácticas de los paises del CAD/OCDE sobre una modalidad en construcción». Madrid: UCM.

Díaz, J. Manuel (2008): «Crítica de la Razón Moderna». Valencia: Tirant Lo Blanch.

Echart, Enara; Cabezas, Rhina y Sotillo, José Ángel. (2016): «Manual para la Elaboración de Investigaciones en Cooperación para el Desarrollo», Madrid: Catarata.

Gómez, Manuel; Ayllón, Bruno y Albarrán, Miguel (2011): «Reflexiones Prácticas sobre Cooperación Triangular». Madrid: CIDEAL.

González, M. ${ }^{a}$ Inmaculada. García, Mercedes. Rodrígues, Carlos. (2013). «Guía para la cooperación educativa internacional y educación para el desarrollo». Madrid: Biblioteca Nueva.

González, M. ${ }^{a}$ Inmaculada. (2007): Diálogo Intercultural, Derechos Humanos y Diversidad Cultural; en.

González Pérez, T. (coord.): Repensando la multiculturalidad, Anroart Ediciones, Las Palmas de Gran Canaria, PP. $195-217$. Hessel, S. (2009): «Hacia Nuevas Solidaridades: Diez Diálogos sobre Cooperación al Desarrollo», Madrid: Catarata.

Kabunda,M. (2008) "África en la globalización neoliberal: las alternativas africanas", Buenos Aires: revista THEOMAI. Estudios sobre sociedad y desarrollo, no 17. PP. 87-77.

Kabunda,M. (2005): "El desarrollo en África: del estancamiento a la crisis permanente", Madrid: Revista española de Desarrollo y Cooperación, no 16. PP. 9-29.

Kabunda,M. (2011): «África y la Cooperación con el Sur desde el Sur», Madrid: Catarata.

López, Gonzalo y De la Torre, Ignacio. (2000): «Introducción a la Solidaridad Internacional: La Cooperación para el Desarrollo», Madrid: Universidad de Valladolid.

Sotillo, José Ángel. (2011): «El Sistema de Cooperación para el Desarrollo: actores, formas y procesos», Madrid: Catarata.

Sousa De, Boaventura (2008): «Epistemologías del Sur», Utopía y Praxis Latinoamericana, vol. 16, julio- septiembre 2011 (4): 17-39. Disponible en http://www.redalyc.org/articulo.oa?id=27920007003 y recuperado el 14 de julio de 2017. 